\title{
The importance of characterization of materials
}

\section{Opinion}

About $70 \%$ of all technological innovations are, to a certain extent, directly or indirectly linked essentially to materials. In view of this, innovative research tends to seek new ways of promoting the recycling and development of advanced materials, such as industrial solid waste that, after its useful life, is disposed of and destined for industrial landfills. Many of these wastes are, to a large extent, materials with potential to be reinserted, either back to the production cycle, provided they are appropriately recycled, segregated and separated or, when this first attempt is not assertive, these wastes can be used for development of new products, also known in the academy as co-products. These co-products are produced with the use of wastes with specific potentials. In this respect, the characterization of these materials through advanced techniques allows the knowledge of physical, chemical, thermal, structural, etc. properties. In the industry are generated several types of waste in its production cycle such as ferrous, non-ferrous, metallic materials, ceramic materials, biomass, etc. Knowing the production process to which a given waste is generated, it is possible to optimize the production to decrease its generation and / or to know exactly that material / residue in such a way as to apply it in a given process in the future. This knowledge generates added value. Then, the valorization of these residues and their use in the production of new materials widens the knowledge be it in the analysis of the life cycle of that material used initially until the end of its life, in the form of residue. Of course, there is a need for advanced materials processing which involves technology to the point of developing new advanced materials with specific characteristics: bioengineering applications, composites, functional materials, environmental materials, etc. There are several types of materials generated from the production processes and depending on their characteristics they have properties which may be superior
Volume 3 Issue I - 2019

\author{
Alini Luísa Diehl Camacho \\ Laboratório de Caracterização e Valorização de Materiais, Brazil \\ Correspondence: Alini Luísa Diehl Camacho, Laboratório \\ de Caracterização e Valorização de Materiais, Laboratório de \\ Polímeros, Unisinos, Somos infinitas possibilidades, Brazil, \\ Email ALDIEHL@unisinos.br \\ Received: January 18, 2019 | Published: January 23, 2019
}

when compared to the materials originally used in a conventional industrial process. For example, adding a specific percentage of a study material to a metal alloy can greatly improve its mechanical properties. Faced with this, it is important to consider that natural resources are scarce and in many cases, are no longer so easily found in nature. The environmental impact caused mainly when one thinks of ore extraction is enormous, when evaluated from the outset. We, as researchers and doctors of knowledge, need to see the productive processes with greater attention mainly what to do with the waste generated. Awareness and responsibility is the legacy that must be given to future generations so that the world becomes equal for all.

\section{Acknowledgments}

Deputy of research of the Sharif University of Technology is thanked for continued support of Seed of Design and Accomplishment of New Processes for Production and Application of Advanced Materials.

\section{Conflicts of interest}

Author declares that there is no conflict of interest. 